\title{
Fidelity in Graphic Novel Translation: A Multimodal Approach
}

\author{
Retno Wulandari Setyaningsih, Universitas Airlangga \\ Titien Diah Soelistyarini, Universitas Airlangga
}

\begin{abstract}
Literary translation is not a simple and easy work due to the peculiar problems that often occur in the process. The problems may be cultural, linguistic, and psychological, or also include style and mode, especially when the translation does not only involve text in narratives but also in images. Focusing on the fidelity in translation, this paper analyzes the Indonesian translation of a literary graphic novel adaptation of Khaled Hosseini's The Kite Runner. By considering the linguistic and cultural differences, the fidelity in translation is examined from both visual and verbal aspects. Utilizing Gonçalves de Assis' chart of fidelity, that includes linguistic fidelity, non-linguistic fidelity, spatio-topia fidelity, typography fidelity, and format fidelity, from 132 pages, there are 32 panels illustrating stark differences or infidelity. different perception and impression due to infidelity in linguistic, nonlinguistic and topography aspects. Yet, there is fidelity to the format, size and position of panels and pictures. Due to the small number of differences found, the Indonesian version of The Kite Runner: Graphic Novel leans towards foreignizing since many borrowings are performed in both verbal and visual aspects.
\end{abstract}

Keywords: comic translation; cultural differences; linguistic differences; translation fidelity; verbal; visual

\section{Introduction}

Translating a literary work often poses a challenge for a translator whose task is not simply transferring meaning and information of the original text from a source language to a target language. Literary translation needs to consider not only linguistic but also nonlinguistic aspects, which include cultural and psychological, as well as style and mode. Furthermore, when a literary text to be translated employs more than just a verbal mode, the challenge becomes even greater. Hence, this clearly applies in the translation of graphic novel, a form of contemporary literature that employs both verbal and visual modes in narrating the story.

Many literary works, either classic or contemporary, have been adapted into graphic novels due to the growing popularity of this new form of literature. Even award-winning novels by famous authors can also be found in graphic novel format, including The Kite Runner by Khalid Hosseini. First published in 2003, the novel has won a number of popular and critical awards, among others the Borders Original Voice Award, the San Francisco Chronicle Best Book of the Year Award, and the South African Boeke Prize. Depicting an Afghan boy, Amir, who felt guilty because he could not prevent his half-brother, Hassan, from getting raped by another boy andhow he redeemed his guilt, the graphic adaptation of Hosseini's novel was published in 2011 and the illustration was done by Fabio Celoni and Mirka Andolfo.

Even though graphic novel may appear similar to comics, they actually differ in nature. According to Zanettin (2014: 7), graphic novel is different from comic book in a sense that it usually contains more than 100 pages and also non-serialised stories printed on good quality paper and glittering full colors. The target readers, on average, are older and more diversified than that of traditional comic book readers, who are mostly male teenagers. It is in line with Kurc (2003) statement cited in Yablonsk (2016: 41) that graphic novel are stories that present a deeper and more mature approach to certain issues and constitute a complete, finished story of a bigger volume and are bound like books and targets mature audience.

As a graphic novel of best seller and award-winner literary work, The Kite Runner is translated into many languages, one of them is Indonesian. This study is intended to reveal the 
fidelity in translating Hosseini's The Kite Runner: Graphic Novel by comparing the English and Indonesian versions. Defined in Webster's English dictionary (2009) as faithfulness, fidelity is "the quality of being accurate, reliable, and exact." While Kolawole and Salawu (2008) forwarded to some translators that fidelity is to transfer the message from the source text to the target text in a word-for-word manner, some others believe that fidelity is to adopt a free method in passing on the message.

Since graphic novel is a combination of words and pictures, the analysis is based on its multimodality. Kress and Van Leeuwen (2001:20) define multimodality as "the use of several semiotic modes in the design of a semiotic product or event". Graphic novel main features are visual and verbal which are connected through certain formal elements such as speech balloons. According to Zanettin (2014: 12), "semiotic systems are co-present and interplay at different levels and are culturally determined along dimensions of space and time. Thus, in a multimodal analysis both elements are significant.

One of the first studies to concern the multimodal nature of the translation of comics was Kaindl (1999) who investigated the interplay between the textual and pictorial content of comics such as Asterix, Tintin, and Peanuts in terms of humor translation. Another scholar, Celotti (2008) in her article entitled The Translator of Comics as a Semiotic Investigator highlights the relevance of the interrelations between the two modes and states that the visual language can be a resource rather than a constraint for the translator. Meanwhile, other studies discussing fidelity in comic translations include Gonçalves de Assis (2016) who elaborates the concept of fidelity and Asimakoulas (2017) that discusses adaptation in comic translation. This study further illustrates the concept of (in)fidelity in translating graphic novel through its visual and verbal elements.

\section{Method}

As this study is intended to illustrate the fidelity in the translation of The Kite Runner: Graphic Novel from English into Indonesian, a close reading and examination is conducted to map the differences between the two versions. The English graphic novel was taken from an electronic version published by Riverhead books in 2011, while the Indonesian version is printed version published by Second Wind Comics in 2013. In finding the fidelity, the table provided by Gonçalves de Assis is utilized in which elements mapped are the linguistic fidelity, non-linguistic fidelity, spatio-topia fidelity, typography fidelity, and format fidelity. Further, the mapping result is interpreted based on different cultural traditions and different sets of conventions for comic translation in English and Indonesian. Thus, this study is quantitatively based since the data are in a form of words and explanations as well as the researchers' interpretation rather than statistics dependence.

\section{Discussion}

\subsection{Linguistic Fidelity}

Gonçalves de Assis (2016) lists linguistic signs as signs written over the page that include those in speech balloons, captions, onomatopoeia, and other lettering spread throughout the background. The most significant linguistic sign worth analyzing is onomatopoeia used in both graphic novels. Onomatopoeia is an imitation of sound which is greatly influenced by surrounding culture (Setyaningsih, 2012). Rosalina (2009) reveals in her study that there is a fundamental difference in structure between Indonesian and English onomatopoeia so that the translation should be dissimilar. However, in the Indonesian version of The Kite Runner, there are many English onomatopoeia borrowed. For example, the sound of telephone ringing which is illustrated in English as ring and written in many variations such as multiple consonant ' $r$ ', vowel ' $i$ ' or consonant ' $g$ ' is literally borrowed $(2013: 5,85)$. Only one time, there appears onomatopoeia kring which is defined in online KBBI as the onomatopoeia for bell (such as, on bikes, telephone, etc.). Other examples of borrowed onomatopoeia are boom, kapoow, pow, crack, ding dong with some alterations, such as reducing the characters, be it vowel or consonant, in the Indonesian versions (2013: 56, 57). 
Furthermore, on page 50 last panel that illustrates a splash of wet rotten fruit against Hassan's body done by Amir to provoke his anger, the onomatopoeia used in English is slllaaapppp since the intended meaning is 'Amir hits or slaps Hassan'. Meanwhile, the Indonesian onomatopoeia is splotch, which is actually an English noun and the meaning is 'a daub, blot, or smear of something, typically a liquid' (Oxford online). On the other hand, some other onomatopoiea are translated using Indonesian, such as the sound of clapping hands, which is translated as plok plok, or the honking sound, which is translated as din din, and the sound of banged door, which is written as blam. Thus, despite the tendency of borrowing English onomatopoeia, there is disloyalty in the way they are on the translated pages.

\subsection{Non-linguistic Fidelity}

Non-linguistic aspect deals with picture portion of the page. In general, the picture portion of the page is similar in both graphic novels analyzed. The arrangement of the panels, the main pictures and colors are mostly similar. Yet, there are aspects worth noting in relation to non-linguistic fidelity. Despite the exact same number of panels, there are significant picture deletions. For example, on page 45, the English version clearly shows a trace of red color on Hassan's bottom pant and some red blotch on the ground, while in the Indonesian version there is no red color on those spots except for the kite's red color. In fact, it is very essential for the story since Amir's guilty feeling begins with this Hassan's sodomized accident. Thus, eliminating this color may lessen the message intended to be delivered in this part.

Figure 1. Hassan walks pass Amir after the accident with a trace of blood (left-English version, 2011: 45) and without any trace (right - Indonesian version, 2013: 45)

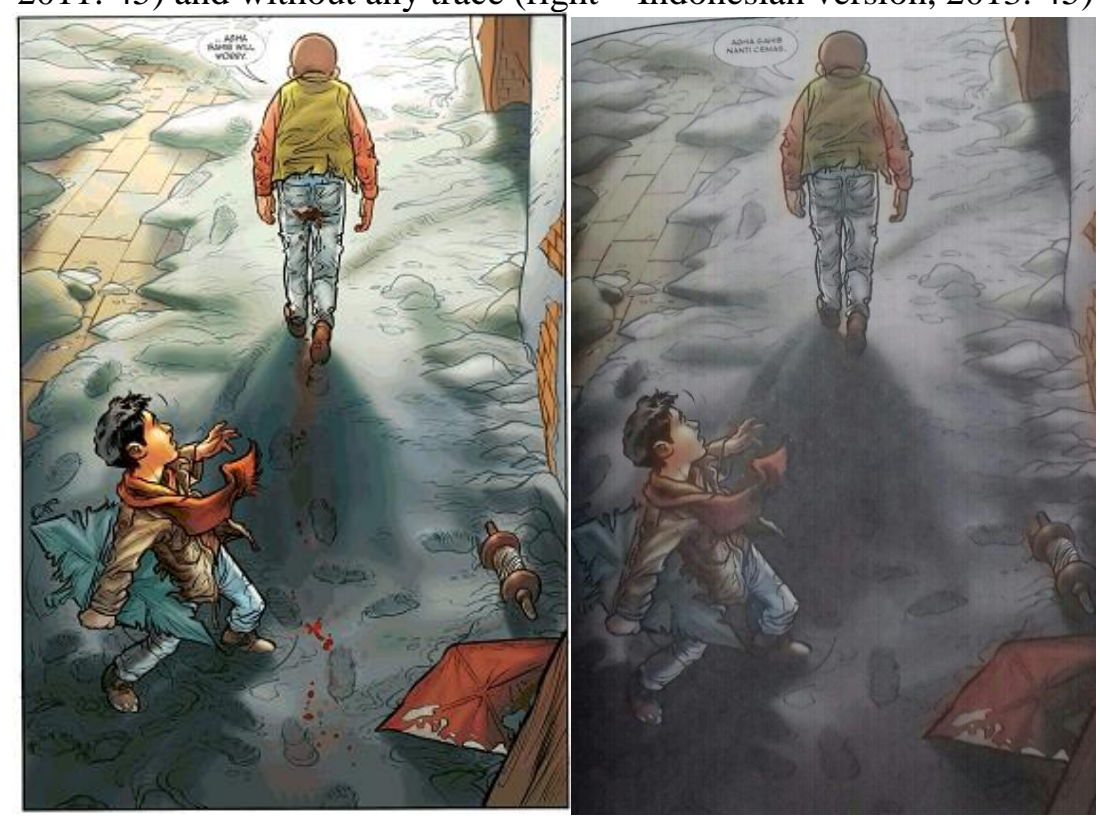

Another example is found on page 111 in which the original version shows a pool of blood as a result of rajam punishment. According to Islamic terminology 'rajam' (Arabic: رجم) is an Arabic word that means 'stoning'. It is primarily a punishment for persons who engage in unlawful sexual relations (which include homosexual relationship). In fact, this panel illustrates the hypocricy of Asef who once sodomized Hassan and then did the same thing to Hassan's son, but he is also the one leading the punishment for others. However, there is a blackened panel with three balloons written Allahu Akbar on the translated version. It does not visualize the victim of rajam but let the readers imagine it themselves. The presence of three speech spiked balloons written 'Allahu Akbar' which means 'Allah is Great' further lead readers' imagination from rajam to Islam. Gonçalves de Assis (2016) states that Zanettin, Rota and Kaindl present examples in which the nonlinguistic signs were often altered to conform to certain visual 
cultures or public segments. In this study, alteration may relate to censorship since homosexuality or sodomy is considered taboo in Indonesian culture (Indonesia - Justice Department, 2008). In addition, rajam is considered as harsh punishment despite the fact that most Indonesians are moslems. Thus, the deletion of the picture may be intended to avoid the stigma that Islam is harsh.

Figure 2. Rajam punishment: the bloody depiction (left -- English version, 2011: 111) and a blank/blackened panel with speech balloons (right - Indonesian version, 2013: 111)
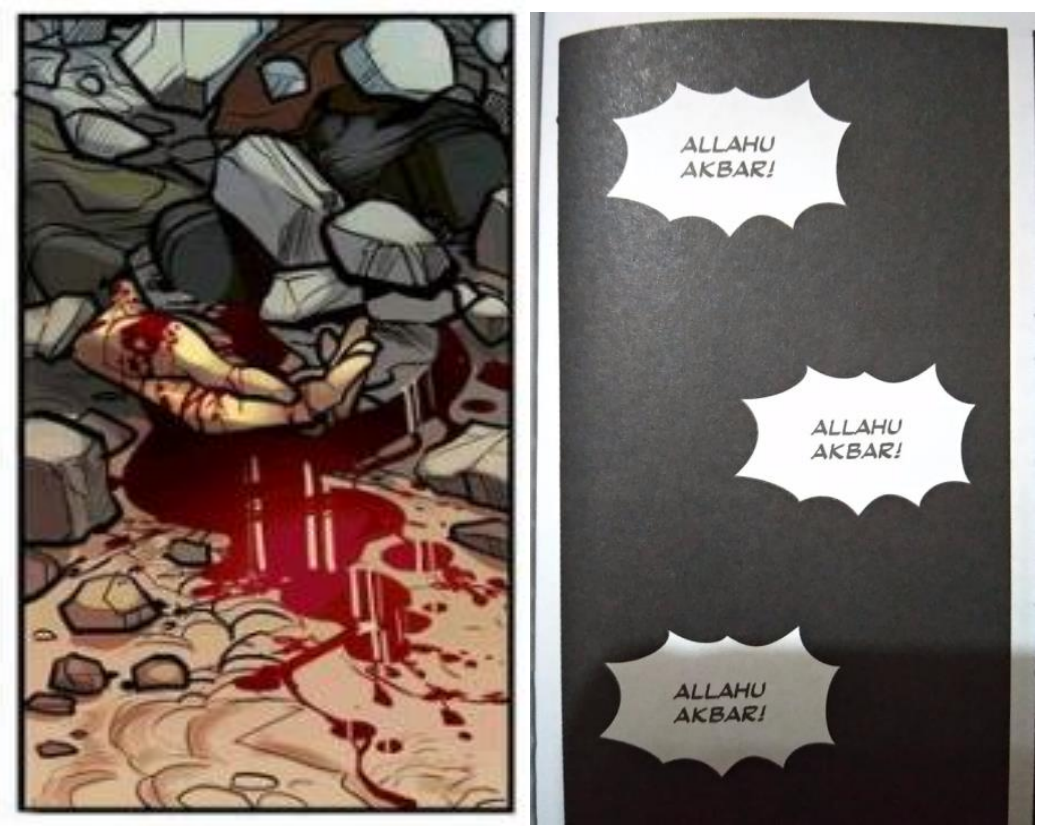

\subsection{Spatio-topia Fidelity}

Groensteen (2007: 21, 28-29) defines spatio-topia as the spatial features of each panel, such as its format, size, and position on the page's surface, which determine its relation to other panels. Regarding to this aspect, the translation proves its fidelity to the source text since the format, size and position on the page's surface is an exact match in the target text. It can be seen from the exact number of pages on both versions. There is also no difference in the order of relation between panels both in the English and Indonesian versions.

\subsection{Typography Fidelity}

Typography concerns with lettering and the physical dimensions of the comic (Rota2015: 83). Regarding the data of this study, there is a high infidelity in relation to typography. One obvious disloyalty can be illustrated in the writing of onomatopoeia. Despite the fact that there are many borrowings, the way those borrowed onomatopoeia written is dissimilar or sometimes opposite to the original lettering. For example, there are deletion of onomatopoeia huff puff (2013: 19, 51), minimized quantity of lettering (2013: 22, 56, 63), increased or decreased of the font number $(2013: 36,72,80)$, etc. In addition, there is also an effort to minimize effect by putting onomatopoeia into a speech balloon (2013: 20, 80). On page 20 , there is a lettering of a dog sound, but on the Indonesian version the onomatopoiea is placed inside a balloon. The same thing also goes in page 80 when Baba Jan is coughing hard, but the sound is inserted in the balloon instead of written out on the panel. 
Figure 3. Topography infidelity shown in the placing of onomatopoeia: integrated with picture (left -- English version, 2011: 20) and inside speech balloon (right - Indonesian version, 2013:

20)

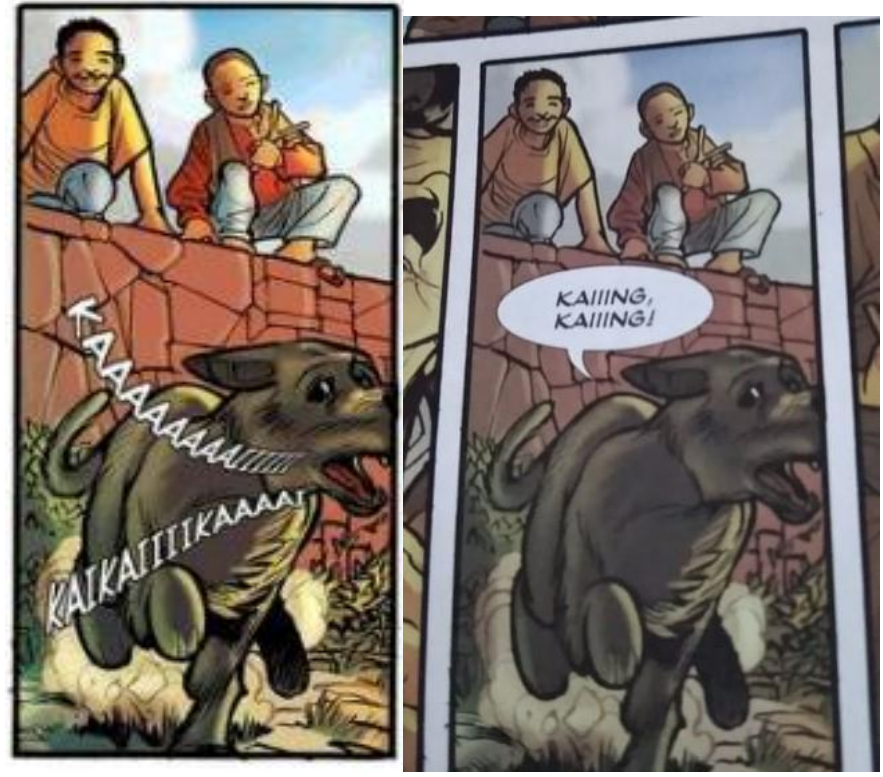

From the data analyzed, it can be stated that the lettering on the Indonesian version tends to differ from the original. One significant feature is that in the Indonesian version the emphasis on the importance of certain onomatopoiea is often shown by using few characters but bigger font. While in English the emphasis is shown through multiplying some characters of the onomatopoiea. For example, in page 22 when illustrating a bombing, the English version wrote booommm twice, with seven and six characters. In Indonesian version, the onomatopoeia was borrowed but there are only four and five characters each. Thus, Indonesian version pays attention more on font size rather than the lenght of onomatopoiea to heighten the emphasis.

\subsection{Format Fidelity}

The last element, format, deals with the established print sizes of graphic novel. Considering to that translating from English into Indonesian tends to result in a longer version, as stated by Murtisari (2014: 16), the font and print size is adjusted in the translated version. The font is slimmer in Indonesian version but slightly bigger compared to the English one. Furthermore, due to longer sentences, the balloons also tend to be bigger and oval in shape rather than round as in the original. As a consequence, there are certain details on the background covered by the ballons. The translated version often sacrifices the pictures in order to preserve the texts in the ballons. Slimmer but bigger font size in the translated version and the tendency of longer translated sentences made the graphic novel seems full with conversations and requires effort to read it.

\section{Conclusion}

Comparing and examining Kite Runner graphic novels indicates that there is fidelity to the format, size and position of panels and pictures. However, there is a tendency toward (in)fidelity in both linguistic and nonlinguistic elements that relate to delivering the message. There is an influence of culture and convention that leads to censoring important aspects of the story. In short, the Indonesian version of The Kite Runner: Graphic Novel leans towards since many borrowings are performed in both verbal and visual aspects. 


\section{References}

Asimakoulas, D. 2017. Synchrony issues in comics. Language transfer and gender-specific characterisation in English translations of Greek Aristophanic comics. Journal of Graphic Novels and Comics. DOI: 10.1080/21504857.2017.1355820

Celotti, N. 2015. The Translator of Comics as a Semiotic Investigator. In Zanettin, F (ed.). Comics in Translation. New York: Routledge, 44-64.

Gonçalves de Assis, E. 2016. The Concept of Fidelity in Comics Translation. TranscUlturAl, vol. 8.2 (2016), 8-23.

Groensteen, T. 2007. The System of Comics trans by Bart Beaty, Nick Nguyen. Mississippi: Univ. Press of Mississippi.

Hussein, K. 2011. The Kite Runner: Graphic Novel. New York: Riverhead Books. 2013. The Kite Runner: Novel Grafis (translated by Budihabsari, E). Bandung: Second Wind Comics.

Indonesia - Department of Justice. Available athttps://www.justice.gov/sites/default/files/eoir/legacy/2013/11/07/IDN102828.E.pdf (Accessed 26 May 2018)

Islamic Terminology. Available at http://islamic-dictionary.tumblr.com/post/5317194442/rajmarabic-\%D8\%B1\%D8\%AC\%D9\%85-is-an-arabic-word-that-means. (Accessed 25 May 2018).

Kaindl, K. 2010. Comics in Translation. In Gambier, Y and Dooeslaer, L. (eds) Handbook of Translation Studies vol. 1. Amsterdam: John Benjamins Publishing Company, 36-40.

Kamus Besar Bahasa Indonesia. Available at https://kbbi.kemdikbud.go.id/entri/ (Accessed 30 May 2018)

Kolawole. S. O. \&Salawu. A. 2008. The Literary Translator and the Concept of Fidelity: Kirkup's Translation of Camara Laye's L'Enfant noir as a Case Study. Translation Journal, 12(4). Retrieved May 21, 2018, from http://www.accurapid.com/journal/46lit.htm

Kress, G and Van Leeuwen, K. 2001.vMultimodal Discourse: The Modes and Media of Contemporary Communication. London: Arnold.

Murtisari, E.T. 2014. Translation and Literary Misesis: The Case of The Nobel Nominee Pramoedya Ananta Toer. In Conti, C and Gourley. J. (eds) Literature as Translation/Translation as Literature. New Castle: Cambridge Scholar Publishing, 1629

Rosalina, Fuji. 2009. Deskripsi Semantik Onomatope dalam Komik Serial Detektif Conan. Unpublished undergraduate thesis.

Rota, V. 2015. Aspects of Adaptation: The Translation of Comics Formats. InZanettin, F (ed.). Comics in Translation. New York: Routledge, 79-98.

Setyaningsih, R.W. 2012. Strategies and Methods of Translating Onomatopoeia. ELITE Conference. Malang: UIN Maulana Malik Ibrahim Malang, 221-234.

The Oxford English Dictionary. Available at http://oxforddictionaries.com/words/the-oxfordenglish-dictionary. (Accessed 27 May 2018).

Yablonsky, M. 2016. Text and Image in Translation. CLEaR, 2016, 3(2), 40-51

Zanettin, F. 2015. Comics in Translation: an overview. In Zanettin, F (ed.). Comics in Translation. New York: Routledge, 1-22. 